\title{
İşletme Performanslarının Karşılaştırılması: BIST'te Promethee Yöntemiyle Bir Uygulama
}

\author{
Hüseyin ÇAVDAR*
}

\author{
Sevinç GÜLER ÖZÇALIK ${ }^{* *}$
}

$\ddot{O} Z$

Bu çalışmada, Borsa İstanbul Metal Eşya, Makine Endeksinde yer alan 2012-2016 yılları arası faaliyette bulunan 23 adet isletmenin Oran Analizi ve Ekonomik Katma Değer (EVA) yöntemi ile performansları ölçülmüş̧ür. Çalışmada kullanılan oranlar esas faaliyet kâr marjı, özsermayelaktif toplamı, cari oran, faiz, amortisman ve vergi öncesi kâr (favök) marjı, likidite oranı, net kâr marjı, fiyat-kazanç oranı, piyasa değeri/defter değeri, pay başına kâr, mali borç/özsermaye' dir. Oran Analizi ve EVA yöntemlerine göre performansları ölçülen işletmelerin karşılaştırılmasında Çok Kriterli Karar Verme Tekniklerinden olan Promethee sürecinden yararlanılmıştır. Bulgulara göre yıllar bazında oran analizi sonuçları ile EVA analizi sonuçları farklılık arz etmekte, iki yöntemin çıktılarının farklı değerlendirilmesi gerekmektedir.

Anahtar Kelimeler: Iş̧letme Performansl, Çok Kriterli Karar Verme, Promethee Yöntemi

JEL Sinıflandırması: : C44, C65, G10

\section{Comparison of Firm Performances: An Application on BIST with Promethee Method}

\section{ABSTRACT}

In this study, the performances of the 23 enterprises includedin the Borsa Istanbul Metal Goods, Machinery Index between 2012-2016 were measured using Ratio Analysis and Economic Value Added (EVA) method. The ratios used in the study are the operating profit margin,total equity I total assets, current ratio, earning before interest,taxes depreciation and amortisation (ebitda) margin, liquidity ratio, net profit margin, price-earning ratio, market value / book value, profit per share, financial debt / equity. The Promethee process, which is one of the Multi Criteria Decision Making Techniques, was used to compare the enterprises whose performance was measured according to the ratio analysis and EVA methods. According to the findings, the results of the rate analysis and EVA analysis differ between years and the outputs of the two methods should be evaluated differently.

Key Words: Firm Performance, Multi-Criteria Decision Making, Promethee Method.

JEL Classification: C44, C65, G10

\section{GÍRIŞ}

Küreselleşmenin etkisi ile ülkelerarası sınırlar kalkmış bilginin ve sermayenin dolaşım hızı ivme kazanmıştır. Böylesi rekabetin arttığı bir düzende

\footnotetext{
* Dokuz Eylül Üniversitesi, Sosyal Bilimler Enstitüsü İşletme ABD Finans Yüksek Lisans Programı, huseyincavdar1992@gmail.com ORCID bilgisi: 0000-0002-8770-8030

** Doç.Dr. Dokuz Eylül Üniversitesi, İktisadi ve İdari Bilimler Fakültesi, İşletme Bölümü, sevinc.guler@deu.edu.tr ORCID bilgisi: 0000-0002-0423-7510

$\mathrm{Bu}$ çalışma, Hüseyin ÇAVDAR'ın Dokuz Eylül Üniversitesi Sosyal Bilimler Enstitüsü Finansman Yüksek Lisans Programında 2019 yılında sunmuş olduğu "Promethee Yöntemiyle İşletmelerin Performanslarının Karşılaştırılması: BİST’te Bir Uygulama” isimli yüksek lisans tezinden türetilmiştir.
} 
işletmelerin pozisyonlarını korumak ve değerlerini yükseltmek için doğru atılımlarda bulunmaları, değişen yatırımcı profillerini iyi analiz etmeleri ve kaynaklarını en üst düzeyde etkin kullanmaları gerekmektedir. Tüm bu stratejileri belirlemek için işletmeler, performanslarını objektif olarak değerlendirmeli ve esas amaçları olan işletme değerlerini maksimum noktaya taşımak için hedeflerini iyi belirlemeleri gerekmektedir.

Aydın vd. (2007)' e göre finansal performans, bir işletmenin finansal durumunu ve faaliyet sonuçlarını değerlendirmek için yapılmaktadır. $\mathrm{Bu}$ amaçla finansal tablolardaki çeşitli kalemler arasında ilişkiler kurularak finansal analizden yararlanılmaktadır. Böylelikle işletmenin mevcut ve geçmişteki finansal koşulları değerlendirilmekte ve işletmenin güçlü ve zayıf yönleri ortaya konularak, gelecekle ilgili daha sağlıklı daha akılcı planlar yapılabilmektedir.

İşletmeler, piyasalarda yaşanan değişimler sonucu performanslarını ölçme ihtiyaçları ortaya çıkmış ve çeşitli performans ölçüm yöntemleri geliştirilmiştir. Uzun y1llardır uygulanan geleneksel yöntemler gelişen dünyada işletmelerin performanslarını tam olarak yansıtmaması sonucu yeni yöntemler kullanılmaya başlanmıştır. Özellikle son yıllarda popüler olan yöntemlerden biri EVA (Ekonomik Katma Değer) yöntemidir. EVA yöntemi, işletmelerin uzun dönem başarısının ölçülmesinde bireysel ve kurumsal yatırımcılar tarafından son yıllarda yaygın bir şekilde kullanılmaktadır. $\mathrm{Bu}$ çalışmada performans ölçümüne literatürde yaygın şekilde kullanılan oran analizi ve EVA yöntemleri kullanılmıştır. Oran analizi işletme içi kaynaklardan elde edilip finansal tablolar aracılığıyla hesaplamakta, kolay ve anlaşılır sonuçlar sunmaktadır. EVA, işletmelerin bir dönemde katlandığı sermaye maliyetini elde ettiği faaliyet kârından çıkarmaları sonucu oluşan değerdir. Özellikle finansal performans ölçümünde "değer" kavramı ile ön plana çıkmaktadır. EVA yöntemi, finansal performansın ölçümünde bir işletmede hangi birimlerin değer yarattığını, hangi birimlerin değer yaratmadığını belirlemektedir. Çalışmada iki performans ölçüm yöntemlerinin Çok Kriterli Karar Verme (ÇKKV) tekniklerinden olan Promethee yöntemi kullanılarak karşılaştırılması amaçlanmıştır. Bu yöntem seçenekleri üstünlük değerlerine göre sıralayarak Promethee I Kısmi Siralama ve Promethee II Tam Sıralama sonuçlarını göstermekte ve seçilen kriterlere göre sıralama yapmaktadir.

Çalışmada bundan sonraki bolümde konu ile ilgili yapılmış olan çalışmalar özetlenmekte, ardından çalışmanın veri seti ve yöntem hakkında bilgi verilmektedir. Bulgular bölümünde Prmethee yöntemine göre oran analizi sonuçları ve EVA yöntemi sonuçları karşılaştırılmaktadır. Sonuç bölümünde araştırma bulgularından elde edilen sonuçlar tartışılmaktadır.

\section{LITERATÜR TARAMASI}

ÇKKV yöntemlerinden olan Promethee siralama yöntemi finansal karar alımlarından, tedarikçi seçimine, pazarlama uygulamalarından performans ölçümlerine kadar birçok araştırma alanında uygulanmaktadır. Manzano vd. (2004), İspanya'da marina trafiğginin etkin yönetilebilmesinde, Dağdeviren ve Eraslan (2008) yarı mamul üretiminde tedarikçi seçiminde, Athawale ve 
Chakraborty (2010) kuruluş yeri seçiminde, Özgüven (2012) alışveriş sitelerinde müşteri tercihlerini belirlemesinde, Onan (2014) İzmir ilinde konut satın alımında müşterilerin beklentilerinin belirlenmesinde Promethee yöntemini kullanmıştır.

Finans alanında yapılan çalışmalardan bir kısmı aşağıdaki gibi özetlenebilir;

Albadvi vd. (2007), Tahran Borsasında işlem gören pay senetlerinin seçiminde Promethee yöntemini kullanmışlardır. Bunun için öncelikle yatırımcıların anket yöntemi kullanılarak tercih kriterleri belirlenip, yatırım yapılacak sektörler ve işletmeler tespit edilmiştir. Akkaya ve Demireli (2010), Promethee yöntemi ile halka açılma kararı veren işletmenin maliyet, ulaşılabilirlik, etkinlik ve imaj kriterlerini açısından değerlendirmişlerdir. Qu vd. (2011), Şangay Borsasında işlem gören ve büyüme potansiyeli olan 20 işletmenin performanslarını Promethee yöntemi ile ölçmüşlerdir. Çalışmaya göre Promethee yöntemi değer odaklı olup, yatırım kararı verme sürecinde etkili bir yöntemdir. Şahin ve Akkaya (2013), 2011 yılında İMKB-50 Endeksinde yer alan işletmelerin pay senetlerinde etkin portföy oluşturmak için Promethee yöntemi kullanmışlardır. Portföy oluşturmada temettü, işlem miktarı, volatilite ve işlem hacmi ölçütleri kullanılarak optimal sıralama gerçekleştirilmiştir. Bağcı ve Rençber (2014), 2006-2012 yılları arasında 10 adet halka açılmış özel banka ile kamu bankalarının kârlılık performanslarını Promethee sıralama yöntemiyle analiz etmişlerdir. Çalışkan ve Eren (2016), özel, kamu ve yabancı mevduat bankaların performanslarını ölçmek amacıyla 2010-2014 yılları arasında 10 adet finansal oranı Promethee yöntemi ile analiz etmişlerdir. Analiz sonucunda Promethee yöntemiyle diğer yöntemlerin birbiriyle uyumlu olduğu sonucuna ulaşılmıştır. Ömürbek ve Eren (2016), 2005-2014 yılları arasında gıda sektöründe yer alan işletmelerin performanslarını 13 finansal oran kullanarak Promethee, Moora ve Copras yöntemleri ile karşılaştırmıştır. Apan ve Öztel (2018), imalat sektöründe yer alan işletmelerin finansal performansını oran analizleri ile Entropi, Standart Sapma, Critic ve Ortalama Ağırlıklandırma Yöntemleri karşılaştırmışlardır. Çalışma sonucunda Entropi Ağırlıklandırma Yönteminin diğer yöntemlere göre daha rasyonel ve objektif sonuçlar elde etme gücüne sahip olduğu saptanmıştır.

\section{ARAŞTIRMANIN VERI SETI VE METODOLOJISİ}

Çalışmada Borsa İstanbul Metal Eşya, Makine Endeksinde (XMESY) 2012-2016 yılları arasında yer alan işletmelerin performansları ilk olarak finansal oranlar aracılığı ile ardından EVA yöntemi aracılığı ile Promethee yöntemi kullanılarak sıralanacak ve karşılaştırma yapılacaktır

\section{A. Araştırmanın Veri Seti}

Çalışmada endeks kapsamında yer alan 23 adet işletmenin verisi kullanılmıştır. Analizde yer alan işletmelerin listesi Tablo 1'de gösterilmektedir. Aynı şekilde Tablo 2, analizde kullanılan oranları göstermektedir. 
Hüseyin Çavdar \& Sevinç Güler Özçalık / Işsletme Performanslarının Karşılaştırılması: BIST'te Promethee Yöntemiyle Bir Uygulama

Tablo 1. Çalışmada Yer Alan İşletmeler

\begin{tabular}{|c|c|c|}
\hline Sira & Kod & İșletme Adı \\
\hline 1 & Alcar & ALARKO CARRIER \\
\hline 2 & Asuzu & ANADOLU İSUZU \\
\hline 3 & Arclk & ARÇELIKK A.Ș. \\
\hline 4 & Bfren & BOSCH FREN SISTEMLERİ SANAYİ VE TICARET A.Ș. \\
\hline 5 & Ditas & DİTAŞ DOĞAN YEDEK PARÇA İMALAT VE TEKNİK A.Ş. \\
\hline 6 & Egeen & EGE ENDÜSTRİ VE TİCARET A.S. \\
\hline 7 & Emkel & EMEK ELEKTRIKK ENDÜSTRİSİ A.Ș. \\
\hline 8 & Fmızp & FEDERAL-MOGUL İZMİT PISTON VE PIMM ÜRETIMM TESISLERİ A.Ș. \\
\hline 9 & Froto & FORD OTOMOTIV SANAYİ A.Ș. \\
\hline 10 & Gerel & GERSAN ELEKTRIKK TİCARET VE SANAYİ A.Ș. \\
\hline 11 & İheva & İHLAS EV ALETLERİ İMALAT SANAYİ VE TİCARET A.Ș. \\
\hline 12 & Karsn & KARSAN OTOMOTIV SANAYİI VE TİCARET A.Ș. \\
\hline 13 & Katmr & KATMERCILER ARAÇ ÜSTÜ EKİPMAN SANAYİ VE TİCARET A.Ș. \\
\hline 14 & Klmsn & KLIMMASAN KLİMA SANAYİ VE TİCARET A.Ș. \\
\hline 15 & Maktk & MAKİNA TAKIM ENDÜSTRİSİ A.Ș. \\
\hline 16 & Otkar & OTOKAR OTOMOTIV VE SAVUNMA SANAYİ A.Ș. \\
\hline 17 & Parsn & PARSAN MAKİNA PARÇALARI SANAYİI A.Ș. \\
\hline 18 & Silvr & SILVERLİNE ENDÜSTRİ VE TİCARET A.S. \\
\hline 19 & Toaso & TOFAȘ TÜRK OTOMOBİL FABRİKASI A.Ș. \\
\hline 20 & Prkab & TÜRK PRYSMİAN KABLO VE SİSTEMLERİ A.Ş. \\
\hline 21 & Ttrak & TÜRK TRAKTÖR VE ZİRAAT MAKİNELERİ A.Ş. \\
\hline 22 & Vesbe & VESTEL BEYAZ ESYA SANAYİ VE TİCARET A.Ș. \\
\hline 23 & Vestl & VESTEL ELEKTRONIK SANAYİ VE TİCARET A.Ș. \\
\hline
\end{tabular}

\section{B. Araştırmanın Metodolojisi}

bahsedilecektir.

Çalısmanın bu bölümünde Promethee yöntemi ile EVA yönteminden

\section{Promethee Yöntemi}

ÇKKV metotlarından biri olan Promethee (Preference Ranking Organization Method for Encrichment Evaluations) J. P. Brans tarafindan 1982 yılında geliştirilmiştir. Esas olarak Promethee I Kısmi Sıralama ve Promethee II Tam Sıralama kısımlarından oluşan bu yöntem, alternatifleri arasındaki ikili ilişkileri de göstermesinden ve kriterlerdeki ağırlıkları karar vericinin tercihine bırakılması bakımından diğer karar verme yöntemlerinden ayrılmaktadır. Seçenekler arasında en iyi alternatifi bulmayı sağlayan bu yöntem aşamaları genel olarak şu adımlardan oluşmaktadır (Brans vd., 1986: 228-233):

1) İlk olarak değerlendirilmeye alınacak alternatifler ve kriterler belirlenmekte, bu kriterlere ağırlıklar verilerek karar matrisi oluşturulmaktadır. Matriste alternatifler sütun olarak, kriterler ise satır olarak hazırlanmakta olup Tablo 3' te gösterilmektedir. Burada gösterilen $\mathrm{K}=(1,2,3,4 . . \mathrm{n})$ ölçüt sayısını, $\mathrm{A}=(1,2,3,4 . . \mathrm{n})$ alternatifleri göstermektedir.

Tablo 3. Karar Matrisi

\begin{tabular}{|l|l|l|l|l|l|}
\hline & $\mathrm{K}_{1}$ & $\mathrm{~K}_{2}$ & $\mathrm{~K}_{3}$ & $\cdots \ldots \ldots$ & $\mathrm{K}_{\mathrm{n}}$ \\
\hline $\mathrm{A}_{1}$ & & & & & \\
\hline $\mathrm{A}_{2}$ & & & & & \\
\hline $\mathrm{A}_{3}$ & & & & & \\
\hline$\ldots \ldots$ & & & & & \\
\hline $\mathrm{A}_{\mathrm{n}}$ & & & & & \\
\hline
\end{tabular}

Kaynak: Deshmukh, 2013: 29 
2) Yapılan seçimin niteliğine göre her bir kriter için tercih fonksiyonları oluşturulur. Olağan tipi, U-tipi, V-tipi, Seviyeli tipi, Doğrusal tipi ve Gaussian tipi olmak üzere altı çeşit fonksiyon tipi mevcuttur (Mareschal, 2013: 145-146).

3) Oluşturulan tercih fonksiyonlarında her değerlendirme faktörü için ikili karşılaştırma yapılarak ortak tercih fonksiyonları belirlenir.

4) Oluşturulan tercih fonksiyonları kullanılarak her bir alternatif için pozitif ve negatif değerler belirlenmektedir.

Alternatiflerin tercih indekslerini hesaplamak için $\mathrm{w}_{\mathrm{i}}(\mathrm{i}=1,2,3 \ldots \mathrm{k})$ ağırlıklarına sahip olan $k$ kriterinden yararlanılmakta ve böylece a ve $\mathrm{b}$ alternatiflerinin tercih indeksi hesaplanmaktadır.

$$
\prod(\mathrm{a}, \mathrm{b}) \frac{\sum_{\mathrm{i}=1}^{\mathrm{k}} \mathrm{w}_{\mathrm{i}} * \mathrm{p}_{\mathrm{i}}(\mathrm{a}, \mathrm{b})}{\sum_{\mathrm{i}=1}^{\mathrm{k}} \mathrm{w}_{\mathrm{i}}}
$$

5) Alternatifler için pozitif ve negatif üstünlük değerleri belirlenir. Tüm alternatifler için $\pi(a, b)$ ve $\pi(b, a)$ değerleri hesaplanmaktadır.

6) Alternatifler için Promethee I kısmi sıralama ile birbiri karşısında tercih edilebilirlikleri ve kısmi öncelikleri belirlenir. Kısmi siralama ile alternatiflerin birbirine karşı tercih edilme durumları, birbiri karşısında farksız olan alternatiflerin belirlenmesi ve birbiri ile karşılaştırılması mümkün olmayan alternatiflerin belirlenmesi sağlanmaktadır.

7) Son aşamada Promethee II ile alternatiflerin tam sıralaması yapılır ve net üstünlük değerlerine göre tüm alternatifler aynı düzlem üstünde büyükten küçüğe doğru sıralanarak tam öncelikler belirlenir. 
Hüseyin Çavdar \& Sevinç Güler Özçalık / Işsletme Performanslarının Karşılaştırılması: BIST'te Promethee Yöntemiyle Bir Uygulama

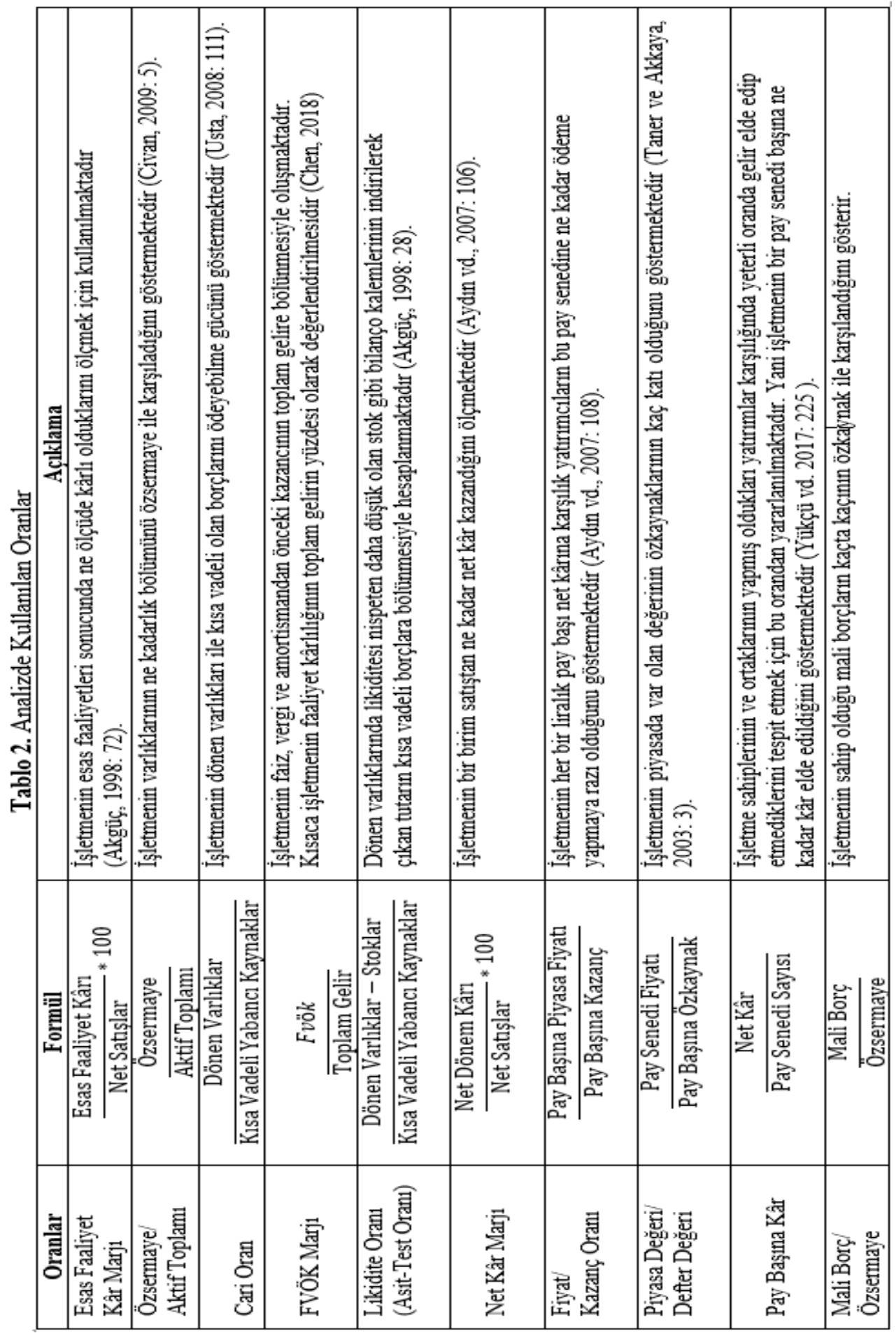




\section{Ekonomik Katma Değer (EVA)}

Çalışmada kullanılan diğer yöntem olan EVA, işletmenin belli bir dönem içerisinde elde edilen kazancından sermaye maliyetini çıkarması sonucu oluşan değerdir. Sermaye elde etmek için katlanılan maliyeti aşan getiri olarak da tanımlanabilir (Gürbüz ve Ergincan, 2008: 245).

En genel ifade ile EVA aşağıdaki formül ile hesaplanmaktadır:

EVA= (Vergi Sonrası Net Faaliyet Kârı (NOPAT) - Sermaye Maliyeti)

Bir diğer ifade ile EVA' yı aşağıdaki formül ile de hesaplamak mümkündür:

EVA = NOPAT $-($ Yatırılan Sermaye* Ağırlıklı Ortalama Sermaye Maliyeti $)$

NOPAT $=$ Faiz ve Vergi Öncesi Kâr * (1-Vergi Oranı)

AOSM=(Özkaynak Oranı*Özkaynak Maliyeti) + (Yabancı Kaynak Oranı*Yabancı Kaynak Maliyeti)

Özkaynak Maliyeti=Risksiz Getiri Oranı + (Beta Katsayıs1*Piyasa Risk Primi)

\section{ARAŞTIRMANIN SONUÇLARI}

EVA Analizinde kullanılmak üzere XMESY endeksinde yer alan işletmelerin bilanço ve gelir tabloları Kamuyu Aydınlatma Platformu' ndan elde edilmiştir. Türkiye Cumhuriyet Merkez Bankası Elektronik Veri Dağıtım Sistemi'nden bankalarca açılan kredilere uygulanan ağırlıklı ortalama faiz oranları (yabancı kaynak maliyetinde), www.investing.com internet sitesinden günlük pay senedi açılış fiyatları (beta katsayısı) ve endeksin ortalama getiri oranı (piyasa risk primi) hesaplanmıştır. Oran Analizinde kullanılacak rasyolar (esas faaliyet kâr marj1, özsermaye/aktif toplamı, cari oran, fvök marjı, likidite oran1, net kâr marj1, fiyat-kazanç oranı, piyasa değeri/defter değeri, pay başına kâr, mali borç/özsermaye oranı) ise www.finnet2000.com internet sitesinden alınmıştır. Elde edilen veriler üzerinden hesaplanan bu değerler, Visual Promethee Academic Edition programıla analiz edilmiştir. İlk aşamada kriterler ve alternatifler belirlenerek karar matrisi oluşturulmuştur. Her bir kriterin ağırlıkları eşit olup EVA bölümü için 1,00 işletmelerin Oran Analizindeki rasyolar için ağırlıkları 0,10 olarak belirlenmiştir. Daha sonra tercih fonksiyonları oluşturulup uygulama için uygun olan $\mathrm{V}$-shape tercih tipi fonksiyon seçilerek analiz yapılmıştır.

\section{A. Oran Analizi Sonuçları}

Çalışmada öncelikle alternatif işletmelerin ve kriterlerin yer aldığ karar matrisleri oluşturmuştur. İşletmelerin performans değerlendirilmesinde kullanılacak kriterler; esas faaliyet kâr marjı, özsermaye/aktif toplamı, cari oran, favök marj1, likidite oran1, net kâr marj1, fiyat-kazanç oranı, piyasa değeri/defter değeri, pay başına kâr, mali borç/özsermaye' dir.

Şekil 1'de Oran Analizi 2012 Y1lı Promethee I (Kısmi Sıralama) sonuçları yer almaktadır. Kısmi sıralamada ölçülen her bir alternatif için +1 ile -1 arasında olmak üzere pozitif ile negatif değerleri hesaplamaktadır. Pozitif çıkan değer ele alınan alternatifin diğer alternatiflere göre oluşan pozitif üstünlüğünü gösterirken; negatif değer ise ele alınan alternatifin diğer alternatiflere göre ne ölçüde zayıf kaldığını göstermektedir (Şahin ve Akkaya, 2013: 75). 2012 yılına ait Kısmi Sıralama analiz sonucu Federal-Mogur ve Alarko Carrier işletmelerinin diğer alternatiflere göre pozitif üstünlükleri bulunduğunu, Karsan Oto ve Anadolu 
İsuzu gibi son sıralarda yer alan işletmelerin ise diğer alternatiflere göre negatif değerleri olduğunu göstermektedir.

Şekil 1. 2012 Yılı Promethee I (Kısmi Sıralama)

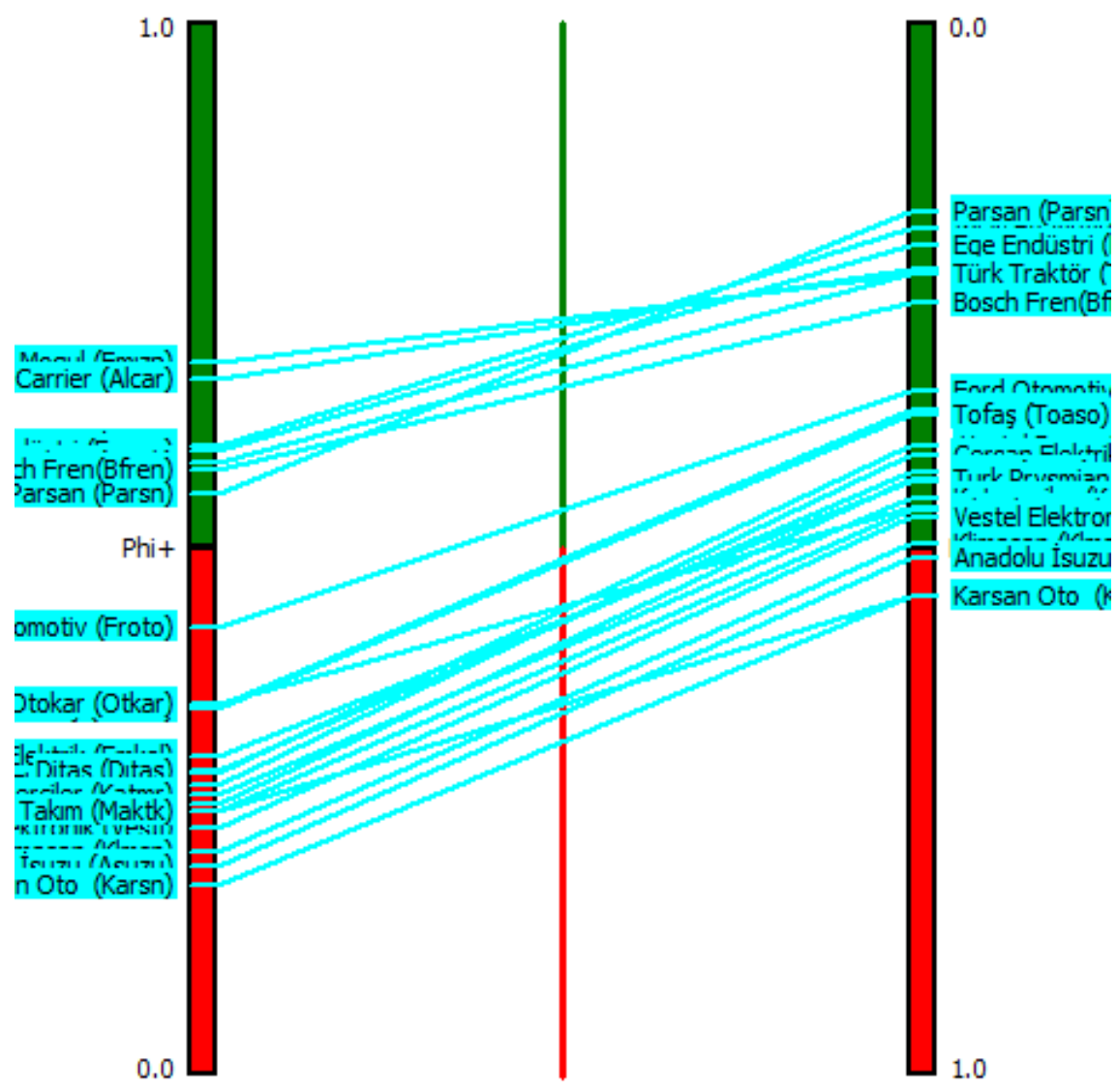

Promethee I Kismi Siralamada en uygun tercih ile en son sirada yer alan tercihler belli olurken orta kısımda yer alan alternatifler arasında net olarak karşılaştırma yapılamamaktadır. $\mathrm{Bu}$ nedenle Promethee II (Tam Sıralama) yöntemi ile alternatifler arasında sıralama gerçekleştirilmektedir. Promethee II (Tam Sıralama) ile pozitif üstünlük değerlerinden negatif üstünlük değerleri çıkartılarak bulunan net üstünlük değerleri üzerinden sıralama yapılmaktadır (Ömürbek vd., 2014: 61). 


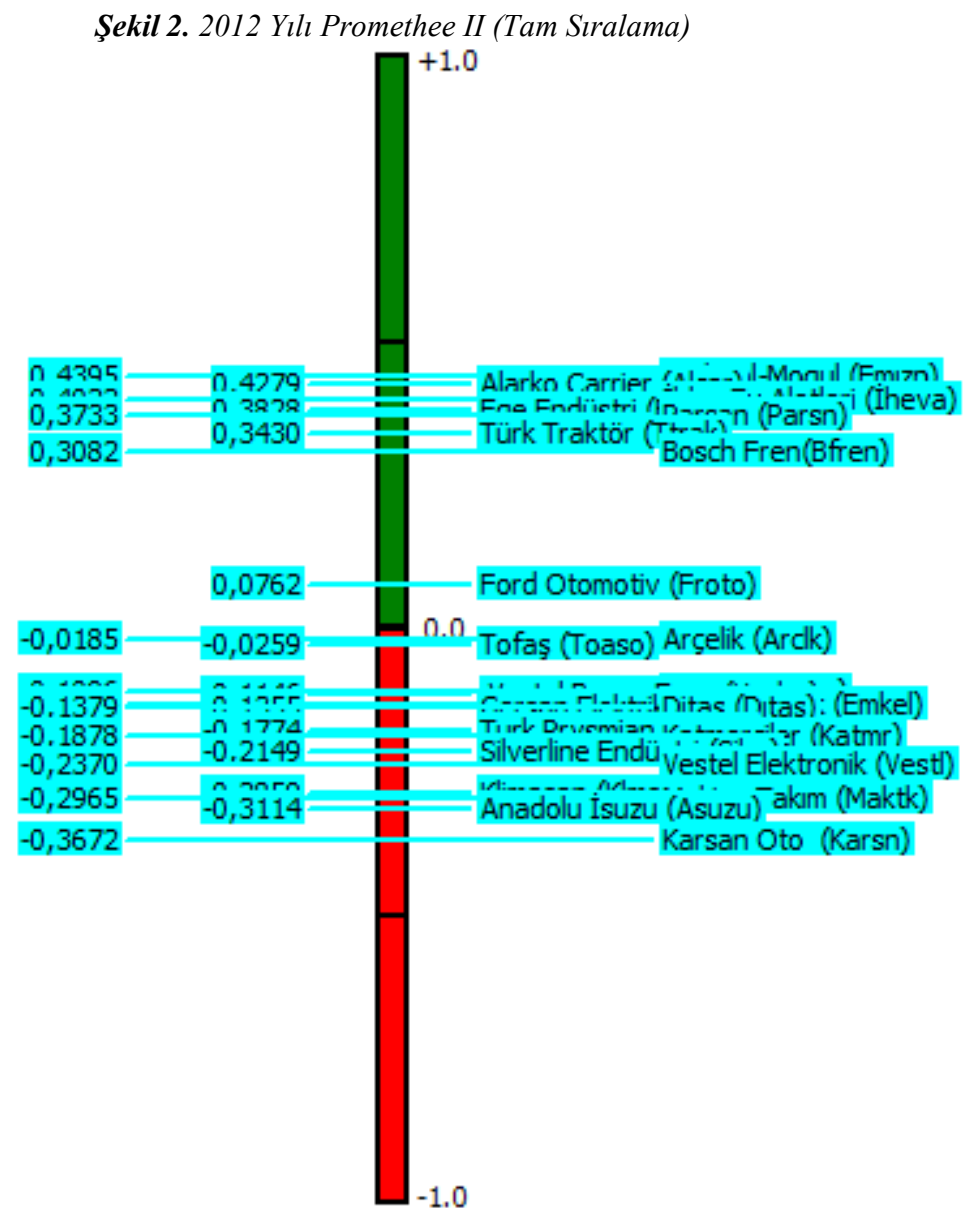

Promethee II ile 0 ile +1 arasında bulunan değerler tercih edilmede ilk sıralarda yer alan değerler olmaktadır (Şahin ve Akkaya, 2013: 76) Bu sıralama yöntemi ile seçilen kriterler doğrultusunda analiz edilen alternatifler arasında en uygun işletme veya işletmeler belirlenir. Şekil 2'de yer alan sıralama sonucuna göre Federal Mogul işletmesi 0,4395 net üstünlük değeri ile tercihler arasında ilk sırada yer alırken, Karsan Oto $-0,3672$ net üstünlük değeri son sirada yer almaktadir. 

BIST'te Promethee Yöntemiyle Bir Uygulama

Şekil 3. 2012 Yılı Promethee Akış Tablosu

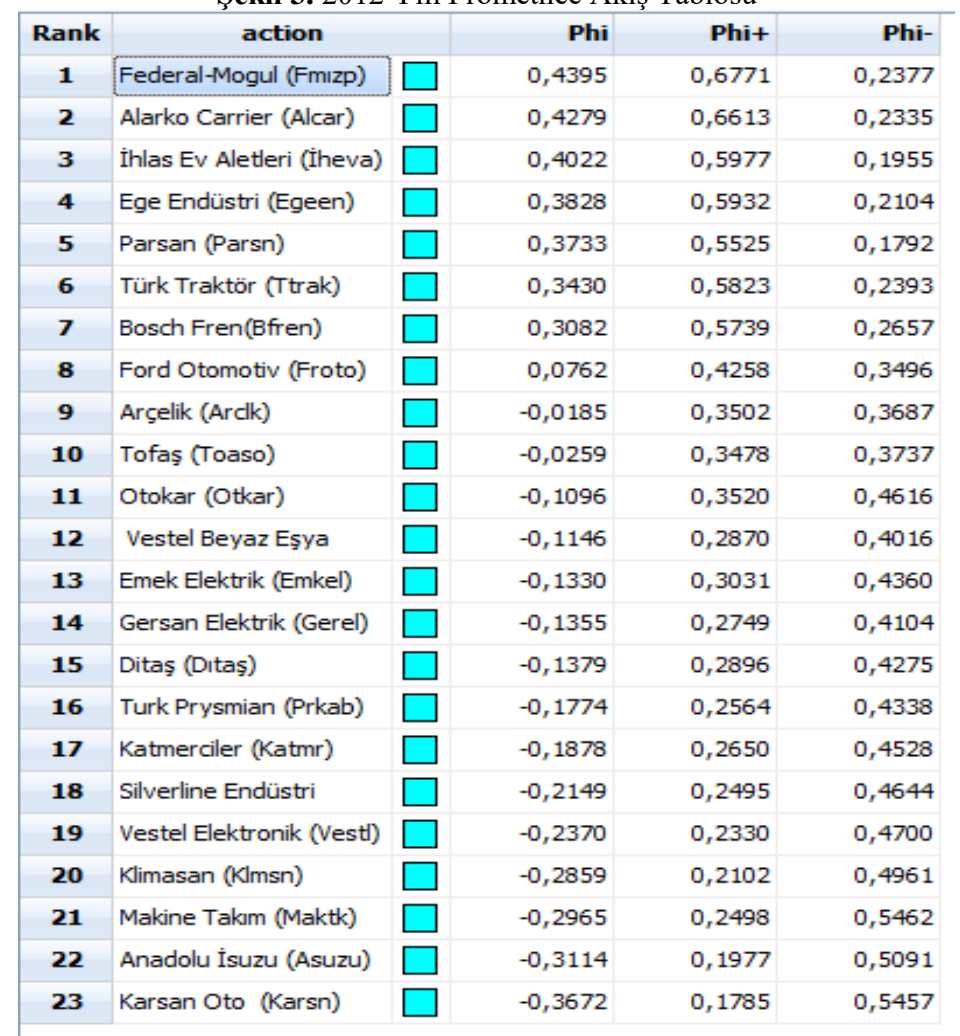

Şekil 3'de çalışmada yer alan işletmelere ait alternatiflerin Promethee II Tam Sıralama sonucuna göre oluşturulan Promethee Akış Tablosu yer almaktadır. Bu tabloda Phi, Phi+ ve Phi- değerleri yer almakta ve Promethee II tablosunda gösterilen alternatiflerin Phi değerlerine göre sıralamasını gösterilmektedir. Phi değerleri Phi+(pozitif üstünlük değerlerinden) Phi-(negatif üstünlük değerleri) çıkarılması sonucu oluşan net üstünlük değerlerini ifade etmektedir (Güney, 2017: 184). Çalışma sonucunda Federal-Mogul işletmesinin net üstünlük değeri 0,4395 ile ilk tercih edilen işletme olurken, Karsan Oto -0,3672 ile son surada tercih edilmektedir. Analiz sonucuna göre sırası ile Alarko Carrier, İhlas Ev Aletleri, Ege Endüstri, Parsan, Türk Traktör, Bosch Fren, Ford Otomotiv net üstünlük değerleri pozitif oldukları için öncelikle tercih edilen işletmelerdir. 
Şekil 4. 2012 Y1lı Promethee GAIA Düzlemi

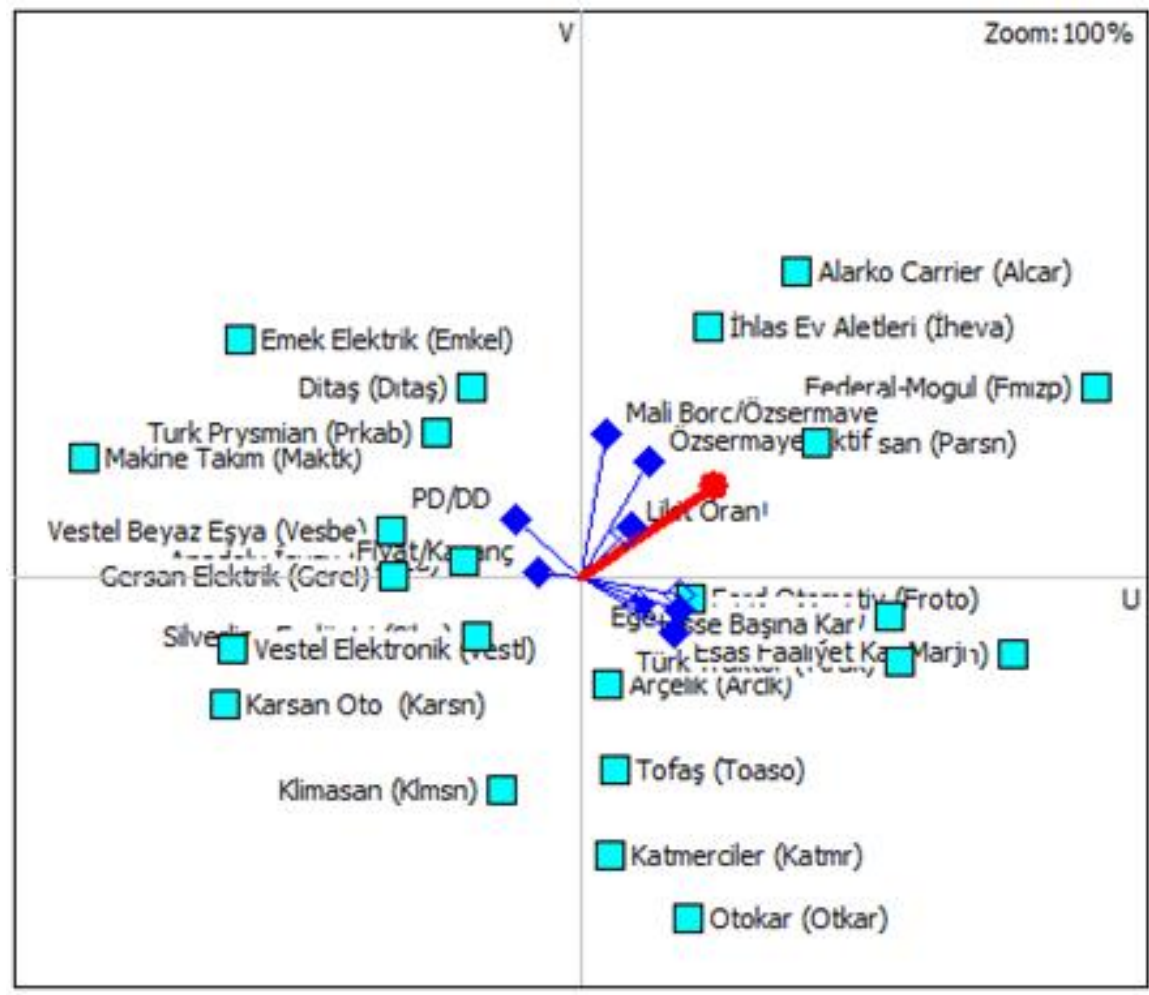

Karar vericilerin kriterlerin ağırlıklarını belirlerken sübjektif olarak davranmalarını önlemek veya birbirine paralel/çelişik olan kriterleri incelemeleri amacıyla Promethee GAIA düzlemi geliştirilmiştir. GAIA düzlemi, ÇKKV süreçlerinde problemlerin çözümünü iki boyutlu olarak ifade etmek için kullanılan gösterim şeklidir. Bu düzlem, aynı yönde hareket eden alternatif ve kriter vektörlerinin uyumu ile ters yönde hareket eden alternatif ve kriter vektörleri arasındaki uyumsuzluğu göstermektedir. Yani düzlem üzerinde bütün kriterler ve alternatifler görülmekte olup hangi kriterin hangi alternatif ile aynı doğrultuda olduğu veya ters ilişki halinde olduğu gözlemlenebilmekte böylece daha sağlıklı kararlar alınması sağlanmaktadır. GAIA düzlemi karar vericilere önem verdikleri performans göstergesine göre hangi işletmenin seçilmesi gerektiği konusunda yardımcı olmakta ve tüm alternatifleri bir düzlem üzerinde toplaması yönünden karar vericilere fikir sahibi olmalarında rehber olmaktadır. Düzlemde yatay eksene yakın olan kalın doğru ise karar vericilere en uygun alternatifi göstermektedir (Şahin ve Akkaya, 2013: 78). Optimal doğruya yakın olan değerler değerlendirilmeye alınan kriterlere göre seçimi yapılacak işletmeleri göstermektedir. Şekil 4'de yer alan düzlemde optimal sonucu gösteren kırmızı kalın çizgiye en yakın olan Alarko Carrier, İhlas Ev Aletleri, Federal-Mogul ve Parsan işletmeleri en başarılı işletmeler olmaktadır. İnce olarak gösterilen çizgilere yakın olan kriterlerin etrafında olan işletmeler ise ele alınan kriter için öncelikle tercih edilmesi gereken işletmeleri göstermektedir. Çalışmamızda, 
Parsan Oto Özsermaye/Aktif oranına göre tercih edilebilecek en iyi alternatifin olduğu gösterilmektedir.

GAIA düzleminde gösterilen kalite değerinin yeşil renkte olması karar vericiler için tatmin edici bir seviyeyi işaret ederken, kırmızı renk ise düşük bir kalite seviyesinde kriterlerin var olduğunu göstermektedir. Çalışmamızda kalite değeri yeşil renk olup performans ölçümünün başarılı sayılması için en az \%70 olmas1 gerekmektedir. Yapılan analiz sonucuna göre çıkan \%71,2 kalite değeri ölçümün başarılı olduğunu kanıtlar niteliktedir.

\section{B. EVA Analizi Sonuçları}

Promethee Diamond 'da her alternatif Phi+ ve Phi- değerlerine göre düzlem üzerinde bir nokta olarak temsil edilmektedir. Düzlem $45^{\circ}$ derecelik açıyla oluştuğu için dik eksende (yeşil-kırmızı eksen) gösterilen Phi net akışlarının nokta şeklinde görülmesi sağlanmaktadır.

Düzlem üzerinde her alternatif için bir koni çizilmekte ve bir koni diğeriyle örtüştüğü zaman Promethee I (Kısmi Sıralama) göre alternatifin diğer alternatife göre tercih edilmesi gerektiği sonucuna ulaşılmaktadır. Ayrıca eğer koniler birbiri ile kesişirse bu durumda alternatiflerin birbiri ile karşılaştırılamayacağı anlamına gelmektedir (Mareschal, 2013: 113). Bu düzlem Phi+ ve Phi- değerlerini aynı anda görselleştirme imkânı da sağlamaktadır. Şekil 5'de yer alan 2012 yılı Promethee Diamond analizi sonucuna göre Türk Traktör alternatifler arasında Phi+ değeri en yüksek olan işletme olarak ilk sırada tercih edilirken, yeşil eksende yer alan diğer işletmeler sırası ile tercih edilen işletmeler olmaktadır. Buna karşılık Karsan Oto, Anadolu İsuzu gibi Phi- değere sahip olan işletmeler için ise karşılaştırma yapılamamaktadır.

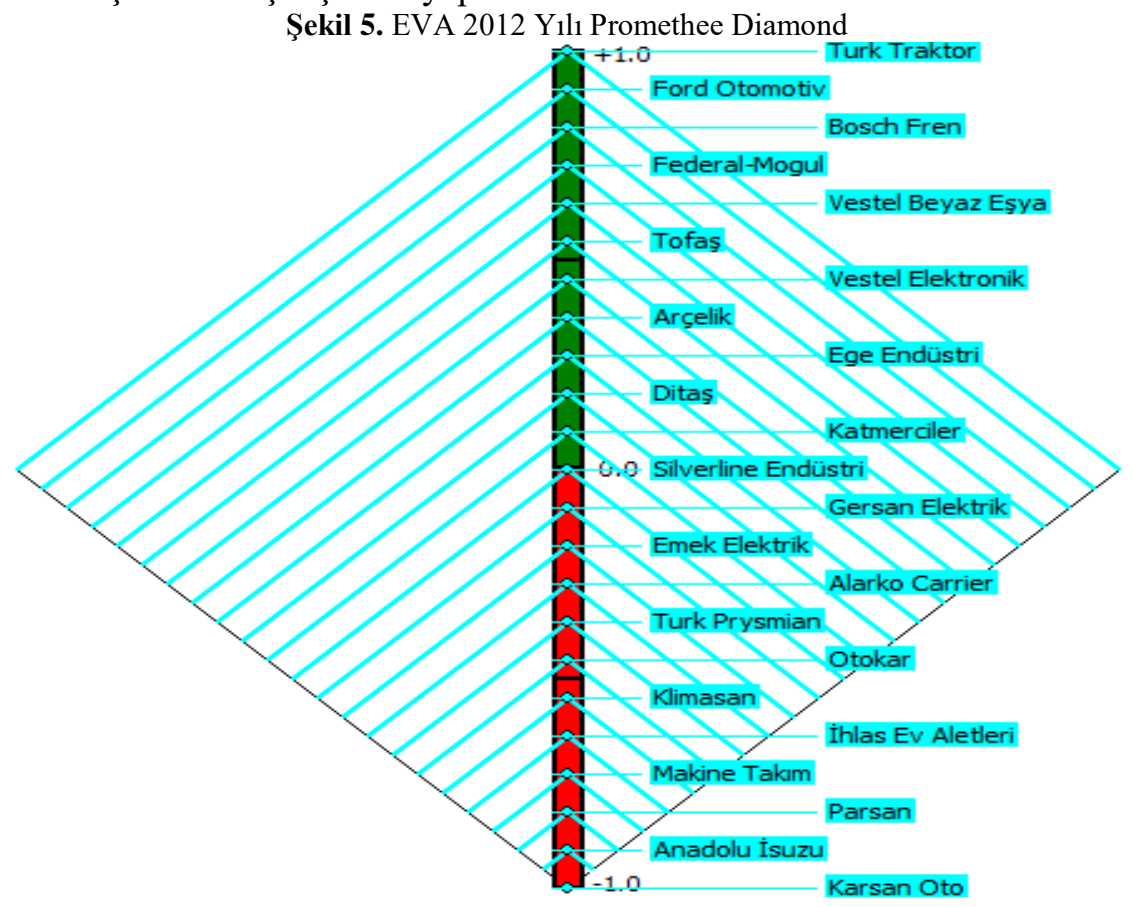


Promethee Network sonuçları tüm alternatifler için düğüm (ağ) şeklinde gösterilmektedir. Bu dügüm şekli Promethee Diamond a karşllık gelen göreceli konumlarda yer alır ve böylece akış değerleri arasındaki yakınlık net bir şekilde görülebilme imkânı sağlamaktadır (Mareschal, 2013: 114). Şekil 6'da yer alan Promethee Network'a göre Türk Traktör' ün değerleri dikkat çekmektedir. Alarko Carrier ve Otokar işletmeler, Arçelik ve Katmerciler işletmeleri de birbiri ile benzerlik göstermektedir.

Şekil 6. EVA 2012 Y11 Promethee Network

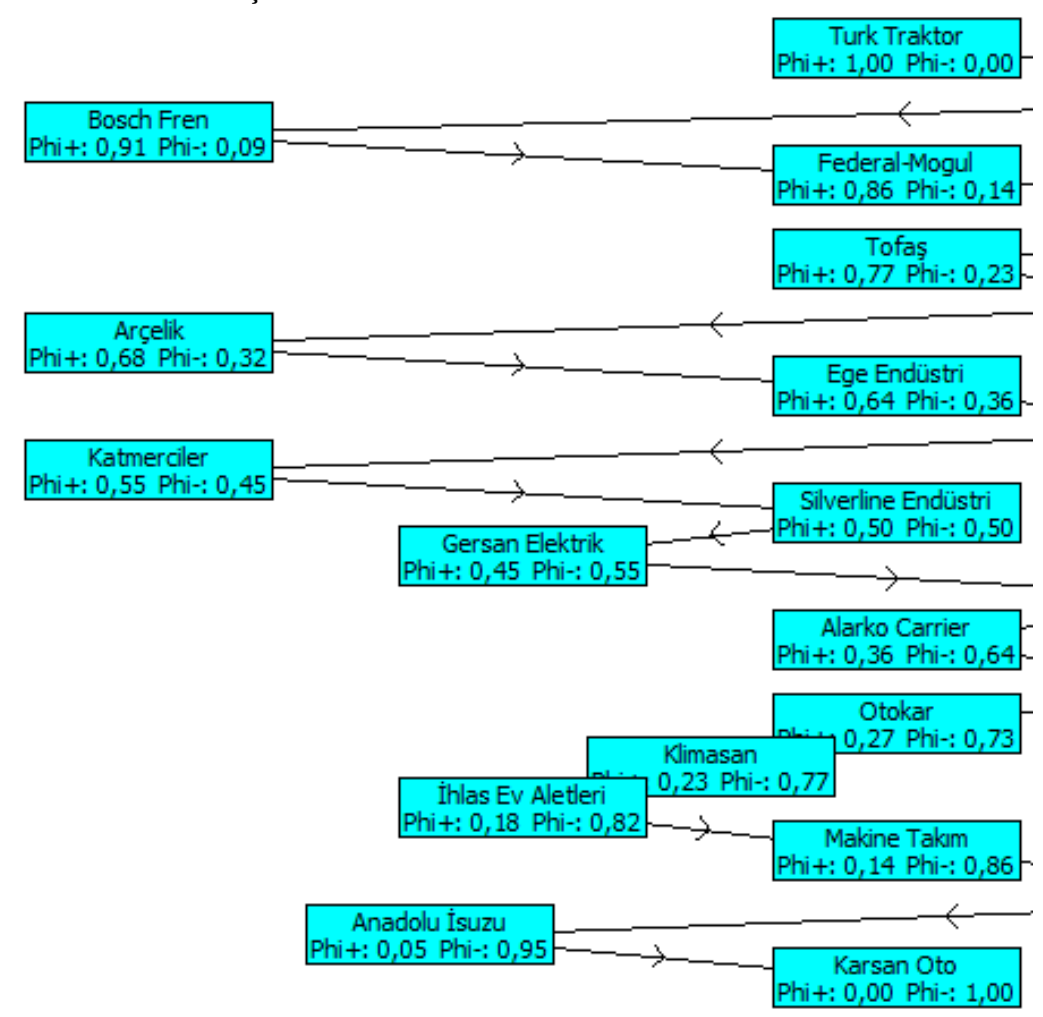

Tablo 4'de Promethee analizi sonucu elde edilen EVA ve Oran Analizi değerlerinin sıralamaları yer almaktadır. Analizin bundan sonraki yıllarına ait hesaplamalar benzer şekilde hesaplanmıştır. Tabloya göre, 2013 y1lında EVA analizine göre Anadolu İsuzu ilk sırada yer alırken, Ege Endüstri Oran Analizi sonucuna göre ilk sırada yer almıştır. Karsan Oto, EVA sonuçlarına göre sonuncu sırada yer alırken, Oran Analizi sıralamasına göre Katmerciler işletmesi son sırada yer almıştır. 2014 yılında EVA ve Oran Analizi sonuçlarına göre Ege Endüstri her iki yöntemde en iyi finansal performans gösteren işletme olmuştur. Ford Otomotiv, EVA sonuçlarına göre sonuncu olurken, Karsan Oto Oran Analizdeki sıralamaya göre son sırada yer almıştır. 2015 yılında EVA ve Oran Analizi sonuçlarına göre Ege Endüstri her iki yöntemde en iyi finansal performans gösteren işletme olmuştur. Karsan Oto EVA değerlerine göre son 
sırada yer almıştır. Oran Analizinde yer alan sonuçlara göre ise Otokar Otomotiv son sırada yer almıştır. 2016 yılında EVA ve Oran Analizi sonuçlarına göre Ege Endüstri her iki yönteme göre ilk sırada yer alırken, Karsan Oto her iki ölçümde de en düşük Phi indeks değerini alarak son sırada yer almıştır.

\section{SONUC}

İşletmelerin finansal tablolarından elde edilen verilerle hesaplanan finansal performans değerleri, işletme ortakları, yöneticiler, yatırımcılar ve diğger karar vericiler için son derece önemli göstergelerden biridir. Günümüzde en uygun performans değerlendirme yönteminin seçiminde çok kriterli karar vermek teknikleri kullanılmakta ve yöneticiler için alternatifler arasında seçim yapmasını kolaylaştırmaktadır. Bu çalışmada ilk olarak Borsa İstanbul'da 2012-2016 yılları arasında sürekli olarak faaliyet sürdüren BİST-Metal Eşya Makine Endeksinde yer alan 23 işletmenin finansal performansları Oran Analizi ve EVA yöntemiyle hesaplamıştır. Ardından bu yöntemlerin karşılaştırılmasında çok kriterli karar verme tekniklerinden Promethee yönteminden yararlanılmıştır. $\mathrm{Bu}$ amaçla matrisleri oluşturulmuş, ardından Promethee I, Promethee II, Akış Tablosu, GAIA düzlemi, Promethee Network ve Promethee Diamond araçları yardımıyla alternatif işletmeler arasında optimal sonuçlar bulunmuştur. Değerler tespit edildikten sonra sonuçlar karşılaştırılarak yatırım yapılmaya en uygun işletmelerin belirlenmesi amaçlanmıştır. Analiz sonucuna 2012 yılında 1,00 Phi değeri ile EVA'ya göre Türk Traktör, Oran Analizi sonucuna göre Federal-Mogul işletmesi 0,4395 net Phi değeri ile ilk sırada yer almışlardır. Karsan Oto, her iki yönteme göre 2012 yılında yatırım yapılmaya en dezavantajlı işletmedir. Diğer yıllara ait performans sonuçları da incelendiğinde benzer bulgular tespit edilmiş ve işletmelerin üstünlük değerlerine göre sıralamalar arasında farklılıkların olduğu sonucuna ulaşılmıştır. 2013 yılında EVA sonuçları dikkate alındığında Anadolu Isuzu işletmesi ilk sırada yer alırken, Oran Analizi sonuçlarına göre 6. sırada yer almıştır.2014 yılında EVA ve Oran Analizi sonuçlarına göre Ege Endüstri her iki yöntemde en iyi finansal performans gösteren işletme olmuştur. Ford Otomotiv, EVA sonuçlarına göre sonuncu olurken, Karsan Oto Oran Analizdeki sıralamaya göre son sırada yer almıştır. 2015 yılında EVA ve Oran Analizi sonuçlarına göre Ege Endüstri her iki yöntemde en iyi finansal performans gösteren işletme olmuştur. Karsan Oto EVA değerlerine göre son sırada yer almıştır. Oran Analizinde yer alan sonuçlara göre ise Otokar Otomotiv son sırada yer almıştır. 2016 yılında EVA ve Oran Analizi sonuçlarına göre Ege Endüstri her iki yönteme göre ilk sırada yer alırken, Karsan Oto her iki ölçümde de en düşük Phi indeks değerini alarak son sırada yer almıştır.

Elde edilen sonuçlarda Ege Endüstri' nin ihracat yoğun bir işletme olmasının etkisi büyüktür. Edilen sonuçlara göre finans yöneticileri için oran analizi gibi geleneksel performans değerlendirme ölçütlerinin yanında, işletmelere artı değer kattığı kabul edilen yeni yaklaşımlardan olan ekonomik katma değer gibi yeni yöntemlerin de birlikte kullanılması son derece önemlilik arz etmektedir. Yöntemlerin birbirinden farklı sonuçlar elde etmesi, yatırımcının karar verme surecini daha da zorlaştırmaktadır. 


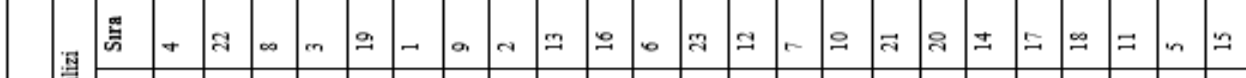

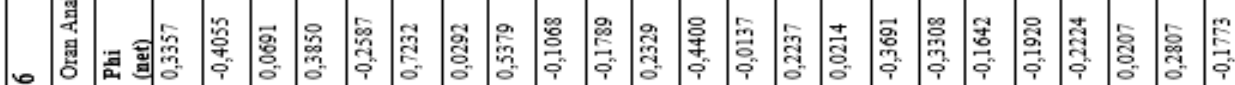
夋

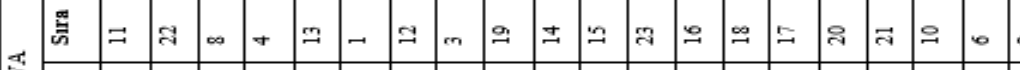

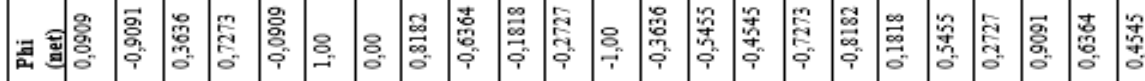

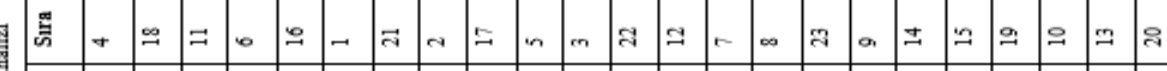
忽 舀

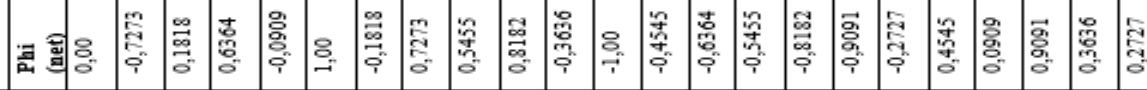

泀 具

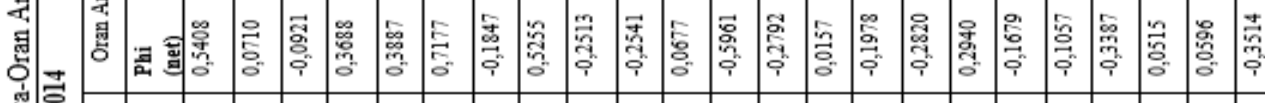
㩊

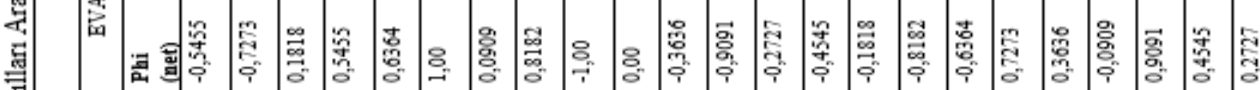
忿 巻

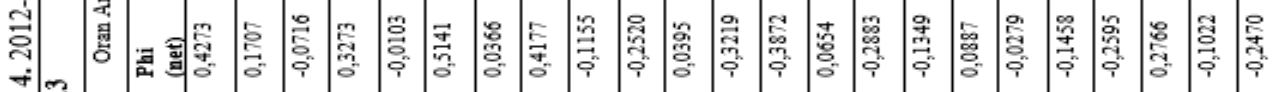
을

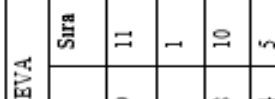

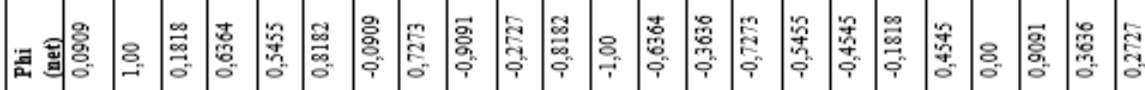

灵

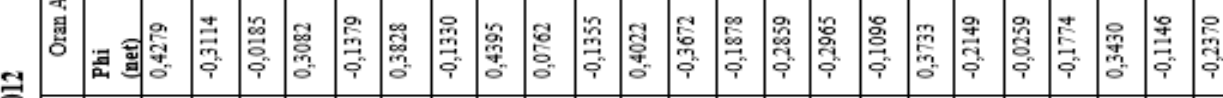

콕

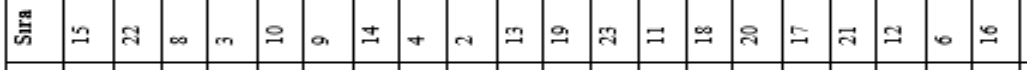

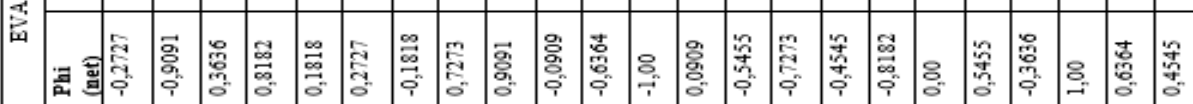

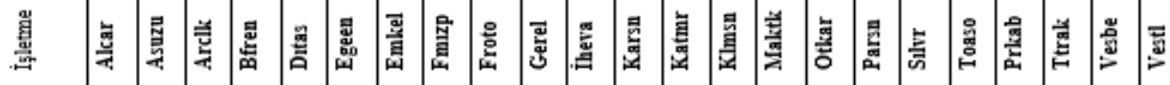




\section{KAYNAKÇA}

Akgüç, Ö., (1998). Finansal Yönetim. (7. Bask1). İstanbul: Avc1ol.

Akkaya, G. C. \& Demireli, E., (2010). Finansal Kararların Verilmesinde Promethee Siralama Yöntemi. Ege Akademik Bakış, 10(3), 845-854.

Albadvi, A., Chaharsooghi, S. K. \& Esfahanipour, A., (2007). Decision Making in Stock Trading : An Application of Promethee. European Journal of Operational Research, 673-683. Doi: 10.1016/j.ejor.2005.11.022

Apan, M. \& Öztel, A., (2018). Ölçek Bazlı Finansal Performansın Promethee Yöntemiyle Belirlenmesi: Farklı Ağırlıklandırma Yöntemlerine Dayalı Karşılaştırmalı Bir Analiz. İsletme Bilimi, 6(1), 207-244. Doi: 10.22139/jobs.357134

Athawale , V. M. \& Chakraborty , S., (2010). Facility Location Selection Using Promethee II Method.Proceedings of the 2010 International Conference on Industrial Engineering and Operations Management.

Aydın, N., Başar, M. ve Coşkun, M., (2007). Finansal Yönetim. (2. Baskı). Eskişehir: Detay.

Bağcı, H. \& Rençber, Ö. F., (2014). Kamu Bankaları ve Halka Açık Özel Bankaların Promethee Yöntemi İle Kârlılıklarının Analizi. Aksaray Üniversitesi İktisadi ve İdari Bilimler Fakültesi, 6(1), 39-47.

Brans, J. P., Vincke, P. \& Mareschal, B., (1986). How to Select and How to Rank Projects: The Promethee Method. European Journal of Operational Research, 24(2), 228-238. Doi: 10.1016/0377-2217(86)90044-5

Chen, J., (2018). Corporate Finance \& Accounting. https://www.investopedia.com/terms/e/ebitdamargin.asp

Civan, M., (2009). Finansal Tablolar Analizi ve Örnek Uygulamalar. Trabzon.

Çalışkan, E. \& Eren, T., (2016). Bankaların Performanslarının Çok Kriterli Karar Verme Yöntemiyle Değerlendirilmesi. Ordu Üniversitesi Bilim ve Teknoloji, 6(2), 85-107.

Dağdeviren, M. \& Eraslan, E., (2008). Promethee Sıralama Yöntemi İle Tedarikçi Seçimi. Gazi Üniv. Müh. Mim. Fak. , 23(1), 69-75.

Deshmukh, S. C., (2013). Preference Ranking Organization Method Of Enrichment Evaluation (Promethee). International Journal of Engineering Science Invention, 2(11), 28-34.

Güney, C., (2017). Visual Promethee ile Yatırımcılar Açısından Sektörlerin Değerlendirilmesi. Turan-Sam Uluslararası Bilimsel Hakemli, 9(34), 177-187.

Gürbüz, O. \& Ergincan, Y., (2008). Şirket Değerlemesi: Klasik ve Modern Yaklaşımlar. İstanbul: Literatür.

Manzano, J. I. C., Quijada, M. T. A. \& Nuño , M. M. C., (2004). Economic Evaluation of the Spanish Port System Using the Promethee Multicriteria Decision Method. https://www.researchgate.net/publication/4806122

Mareschal, . B., (2013). Visual Promethee, Brüksel: VPSolutions.

Onan, A., (2014). Promethee Siralama Yönteminin Konut Projelerinin Değerlendirilmesinde Kullanılmas1. $A K \ddot{U} I \dot{I} B F, 16(1), 17-28$. Doi: 10.5578/jeas.6470

Ömürbek, N., Karaatlı, M., Eren, H. \& Şanl1, B., (2014). Ahp Temelli Promethee Siralama Yöntemi İle Hafif Ticari Araç Seçimi. Süleyman Demirel Üniversitesi İktisadi ve İdari Bilimler Fakültesi, 19(4), 47-64.

Ömürbek, N. \& Eren, H. (2016). Promethee, Moora ve Copras Yöntemleri ile Oran Analizi Sonuclarinin Degerlendirilmesi: Bir Uygulama, Mehmet Akif Ersoy Üniversitesi Sosyal Bilimler Enstitüsü Dergisi, 8(16), 174-187.

Özgüven, N., (2012). Promethee Sıralama Yöntemi İle Özel Alışveriş Siteleri Üzerine Bir Araştırma. Selçuk Üniversitesi Sosyal Bilimler Enstitüsü, 196-201.

Qu, S., Li, H. \& Guo, X., (2011). Application of Interval-Promethee Method for Decision Making in Investing. The Tenth International Symposium on Operations Research and Its Applications.

Şahin, A. \& Akkaya, G. C., (2013). Promethee Sıralama Yöntemi İle Portföy Oluşturma Üzerine Bir Uygulama. Ekonomi ve Yönetim Araştırmaları, 2(2), 67-81.

Taner, B. \& Akkaya, G. C., (2003). İşletme Değerini Belirleme Yöntemleri ve Farklı Sektörlerdeki İşletmeler Üzerine Bir Uygulama. Ege Akademik Baklş, 3(1), 1-7. 
Usta, Ö., (2008). Işsletme Finansı ve Finansal Yönetim. (3. Bask1). Ankara: Detay. Yükçü, S. ve diğerleri, (2017). Mali Tablolar Eğitimi. (1. Baskı). İzmir: Kitapana.

\section{SUMMARY}

With the effect of globalization, the borders between countries have been lifted and the circulation speed of information and capital has been accelerated. In a market where such competition is increasing, businesses need to develop the right strategies to maintain their current positions and increase their market values, as well as to analyze the changing investor profiles well and use their resources at the highest level. Therefore, businesses should evaluate their performance objectively and set their goals well in order to maximize their core business values. As a result of the developments in economic conjuncture, businesses have emerged to measure their performance and so a variety of performance measurement methods have been developed. For many years, the performance of businesses has been measured by traditional performance measurement methods based on accounting, but new methods have been started to be used as these ratios do not fully reflect the actual performance of businesses. One of these methods is the Economic Value Added (EVA) method, which is especially popular in recent years and is used by many large companies. Performance measurement methods based on accounting system are preferred by many businesses because they give an idea about the general framework and show the relationship between financial statement items. In addition, they are used by many businesses because they are obtained from internal sources without any cost and the analysis results can be evaluated immediately.

EVA, which is one of the value-based performance measurement methods that takes into consideration the cost of capital used in the enterprise, is not preferred much because it requires expertise and some accounting adjustments are required. When analyzing with performance measurement methods, Multi Criteria Decision Making methods can be used. Because of the ease of use of this method, decision makers prefer most of decision making processes such as financial decisions, facility location, human resource planning, risk analysis, portfolio selection and other areas. By using these computer-aided programs such as Promethee, criteria and alternatives can be accurately identified and all factors can be seen in decision-making processes and businesses are able to determine their positions more firmly. As a result, it is possible for all stakeholders to benefit from the maximum level by making the right decisions.

In this framework, the aim of this study is to compare the performance of businesses in the BIST Metal Goods Machinery Index between 2012-2016 with the Ratio Analysis based on accounting system and Eva analysis which is one of the value based performance methods in Promethee program in order to investigate whether the different performance measurement confirm each other.We usedoperating profit margin, total equity / total assets, current ratio, earning before interest,taxes depreciation and amortisation (ebitda) margin, liquidity ratio, net profit margin, price-earning ratio, market value / book value, profit per share, financial debt / equity ratios for performance measure.As a result 
of the analysis, different ranking results were reached because the two performance criteria were to meet different objectives and did not move exactly in the same direction. 